\title{
JUVENTUDE E REPRODUÇÃO ENTRE OS GUARANI-MBYÁ DA ALDEIA MORRO DA SAUDADE NA PERIFERIA DA CIDADE DE SÃO PAULO ${ }^{1 *}$
}

\author{
YOUTH AND REPRODUCTION OF THE GUARANI-MBYÁ ETHNIC GROUP \\ OF ALDEIA MORRO DA SAUDADE, ON THE PERIPHERY OF THE CITY OF \\ SÃO PAULO
}

Marcos Augusto P. de Azevedo**

Rubens de Camargo Ferreira Adorno***

\begin{abstract}
Azevedo MAPd, Adorno RdCF. Juventude e reprodução entre os Guarani-Mbyá da Aldeia Morro da Saudade na Periferia da Cidade de São Paulo. Rev Bras Crescimento Desenvolv Hum 2007; 17(2):64-73.
\end{abstract}

\begin{abstract}
Resumo: Estudo qualitativo empreendido para compreender as questões que contornam a maternidade e o comportamento reprodutivo de jovens Guarani-Mbyá, moradores da Aldeia Morro da Saudade, localizada na periferia da cidade de São Paulo. Procura-se desvelar os significados atribuídos à maternidade pelas diferentes gerações Guarani, que vivem em uma área territorial restrita, estabelecendo uma interação cotidiana com outros padrões culturais praticados por uma população de não-índios, que vivem no entorno da aldeia. Esse evento é visualizado sob a ótica sociocultural, que estabelece um processo de interação entre a cosmologia que os representa e as ocorrências do presente, apontando para prováveis possibilidades de mudanças ou permanências no seio cultural do universo étnico que os caracteriza enquanto grupo.
\end{abstract}

Palavras-chave: Juventude e Reprodução. Etnia Guarani-Mbyá. Saúde Reprodutiva. Práticas Rituais. Saúde Indígena.

\section{INTRODUÇÃO}

Considerando o que vem ocorrendo com as gerações mais novas das comunidades indígenas, principalmente as localizadas em áreas urbanas, tivemos interesse em pesquisar e compreender como os jovens Guarany-Mbyá, da Aldeia Morro da Saudade, localizada na periferia da zona sul de São Paulo, região de Parelheiros, encaram e vivenciam, atualmente, a maternidade e a paternidade. A escolha teve por motivação o fato dos habitantes dessa aldeia viverem, cotidianamente, especificidades típicas da periferia da grande metrópole, em que se mesclam valores e comportamentos próprios de cidadãos não-índios. Neste contexto, o foco recaiu sobre as particularidades envolvidas nos rituais que contornam a reprodução dos habitantes da aldeia, levando em conta o discurso das diferentes gerações que lá vivem, visando assegurar sua sobrevivência e confirmar sua identidade cultural.

Segundo Farias ${ }^{1}$ os Guarani provêm da grande família lingüística Tupi-guarani que deu origem a diversas etnias indígenas presentes na América Meridional. E, de acordo com Ladeira ${ }^{2}$, a população Guarani estimada no Brasil é de apro-

* Artigo elaborado a partir da dissertação de mestrado intitulada “ Maternidade e Transmissão Cultural: o que os Guarani, residentes na periferia da Capital Paulista, têm a dizer...”, Faculdade de Saúde Pública da Universidade de São Paulo, 2004.

** Doutorando do Departamento de Saúde Materno-Infantil da Faculdade de Saúde Pública / USP e psicólogo-e-mail cchemariajose@bol.com.br

*** Sociólogo, Professor Doutor do Departamento Materno Infantil da FSP/USP, Av. Dr. Arnaldo, 715-2 andar-Cerqueira César/ São Paulo-Capital-CEP 01246-904- e-mail radorno@usp.br 
ximadamente 33 mil pessoas, entre os Kaiowá (20 mil), Nhandéva (7 mil) e Mbyá (6 Mil). Há, no entanto, diferentes estimativas sobre a população indígena no momento do contato com os europeus. Ribeiro ${ }^{3}$ referenciou que a população neste período era de 4 a 6 milhões. Embora não haja um consenso sobre as diferentes estimativas, constata-se que a redução dos povos indígenas foi muito elevada.

Quanto à presença de Guarani em território paulista, Schaden ${ }^{4}$ esclarece que essa história é bastante conhecida, graças aos trabalhos de Nimuendajú e de outros investigadores. Hoje, segundo Barbosa et al ${ }^{5}$ existem no Estado de São Paulo 11 aldeias habitadas por índios Guarani. A que foi abordada pelo presente estudo ocupa uma área demarcada de 26,30 ha.

Partindo do pressuposto de que, guiados por uma Cosmovisão própria, que orienta seu lugar no mundo, em que ritos e mitos estabelecem práticas culturais peculiares na busca da preservação e da expressão cultural de valores que os representam, em diferentes níveis, algumas especificidades emergem no interior da comunidade guarani paulistana, que incitam indagações correlacionadas com o contexto em que vivem seus membros.

Os Guarani, residentes na capital paulista, têm participado de uma convivência próxima e cotidiana com eventos que caracterizam os grandes centros urbanos, especificamente nas regiões periféricas. Isso é decorrente, sobretudo, do caráter cultural que integra sua buscas, tanto no plano material- aqui se destaca a questão sobrevivênciaquanto no pano espiritual, caracterizado pela possibilidade de encontrar uma "terra sem males".

Assim, ao estabelecerem uma interação cotidiana com outros padrões culturais de uma realidade caracterizada por uma população de não índios, que vive no entorno da aldeia, que mecanismos culturais os guarani utilizam para lidar com especificidades originadas dessa contingência específica, a de serem índios urbanos?

Diante da contingência sócio-ecônomica e cultural, como questões, relacionadas à concepção de maternidade, cuidados do parto e do recém nascido, idéias e práticas sobre concepção e contracepção podem vir a sofrer mudanças, de geração para geração, com possibilidade de gerar conflitos no interior da comunidade?
Não podemos ignorar a complexidade de que se revestem os estudos sobre as questões reprodutivas no campo da saúde reprodutiva, a qual atinge maior expressão ao adicionarmos o adjetivo indígena.

Nas sociedades indígenas, como bem lembra Pagliaro ${ }^{6}$, o comportamento reprodutivo das populações é influenciado por uma série de valores socioculturais, nas quais mito e rito adquirem significados específicos. Essa condição engendra, evidentemente, maior complexidade, requerendo observações específicas para análise do fenômeno, que é caracterizado, também, por variar significativamente de uma sociedade para outra.

Buscar entender os significados dessas práticas culturais na conduta que permeia a concepção de um filho requer procedimentos que contemplem valores que fundamentam a cosmovisão dos envolvidos. No caso dos Guarani, as práticas culturais que dão significados ao seu ciclo reprodutivo - a pré-concepção, a concepção, a gravidez e o nascimento - obedecem a uma lógica muito peculiar. Ao tentar identificar alguns desses aspectos, podem surgir subsídios capazes de explicar a notável capacidade de resistência desse povo no enfrentamento de inúmeros reveses que têm acompanhado sua trajetória, ao longo de séculos.

Lopez $^{7}$ destaca que

"segundo a Cosmovisão Guarani-Mbyá, a gravidez das mulheres contorna um meio de comunicação entre o mundo do humano e o mundo sobrenatural. Pode-se considerar que a fecundidade se constitui num vínculo entre o mundo terreno e o mundo sobrenatural. A idéia de reencarnação, do ponto de vista da sociedade Guarani, apresenta um papel importante pelo fato de garantir o diálogo entre gerações passadas e futuras” (p. 38).

Nas práticas culturais que contornam a reprodução dos povos indígenas, o fenômeno da maternidade adquire uma leitura especial, em função da multiplicidade e riqueza simbólica e mítica que o constituem. O conceito de gênero e reprodução reflete uma cosmologia típica reveladora do modo como os membros de uma sociedade constróem o seu universo e pensam sobre si próprios. 
Se tais aspectos devem ser considerados na abordagem do tema, vale mencionar que, no campo dos estudos sobre saúde reprodutiva, a Conferência Internacional sobre População e Desenvolvimento (CIPD), realizada no Cairo, em 1994, trouxe um avanço significativo ao introduzir uma nova leitura sobre a ampla temática que envolve as especificidades que caracterizam a reprodução humana, passível de ser considerada em relação aos povos indígenas, por enfocar a questão dos direitos das minorias.

Embora suscitando uma abordagem diferenciada, no sentido de contemplar a complexidade que envolve a maternidade, sobretudo em sociedades indígenas, essas novas conquistas pontuadas pela CIPD podem trazer novas alternativas as consideradas minorias, contemplando saúde reprodutiva e sexualidade e direitos reprodutivos, dentro de uma lógica cultural que atenda às necessidades pautadas em fatores étnicos.

È, portanto, dentro desse nível de reflexão e preocupação que definimos o objetivo central do presente trabalho.

\section{Caminho Metodológico}

Para analisar possíveis mudanças ou permanências culturais acerca da maternidade, advindas do contato com a sociedade urbana periférica nos anos mais recentes, expressas nas manifestações de sujeitos de diferentes gerações e papéis sociais, optamos por explorar categorias que estão diretamente ligadas ao processo reprodutivo. Descrevemos sobre cada uma delas, pontuando especificidades observadas no contexto do trabalho de campo, aqui desveladas como questões que contemplam possíveis reflexões que permeiam suas necessidades no momento presente.

Valemo-nos da contribuição etnográfica como alternativa para criar um caminho metodológico que desse conta das especificidades culturais e das contradições que o grupo indígena, selecionado para o estudo, vivencia no contato com o não índio. Tal escolha, deve-se também a ampla possibilidade que esta alternativa metodológica disponibiliza para que se façam as descrições e observações da realidade cultural desse grupo étnico.
Para registrar as observações, usamos, também, um "diário de campo", que Atkinson e Hammersley ${ }^{8}$ dizem constituir-se, a um só tempo instrumento de registro e interpretação. Adotou-se um procedimento dialético no qual as aproximações sucessivas, tais como a ida a campo, visitas, entrevistas, eventos ocorridos e presenciados constituíram uma forma de conhecimento e de análise.

As entrevistas que, em grande parte, foram gravadas, seguiram um roteiro temático, previamente elaborado para o estudo. Algumas foram realizadas individualmente; outras possibilitaram a flexibilidade necessária para uma narrativa autônoma ou compartilhada, sobretudo por parte dos adolescentes. Foram realizadas 21 entrevistas individuais e 3 seções de entrevistas em grupos, assim distribuídas:

a) Entrevistas em grupo com jovens na faixa etária dos 12 aos 17 anos, em média 12 a 15 participantes. Cinco entrevistas individuais com jovens, com o intuito de detalhar algumas opiniões ou experiências pessoais, cuja exposição, no contexto grupal, era inviável.

b) 6 entrevistas com mulheres, mães, de diferentes faixas etárias;

c) 2 entrevistas com jovens professores Guarani, de ambos os sexos;

d) 2 entrevistas com 2 caciques - o atual e anterior;

e) Uma entrevista com parteira e com dois agentes de saúde indígena, de ambos os sexos.

As observações nas visitas à aldeia, o registro anotados no diário de campo e o conteúdo das entrevistas serviram como orientação para análise das "falas" que, após cuidadosas transcrições e leituras, vieram a constituir o material empírico para análise.

O estabelecimento de categorias foi essencial pois, de acordo com SPINK $^{9}$, elas constituem importantes estratégias lingüísticas, estando presentes na própria organização da linguagem (verbal, escrita, gestual, icônica).

Sistematizou-se, então, o ciclo reprodutivo de acordo com as suas diferentes fases como estratégia para escolha das quatro categorias representativas do eixo temático, as quais são as seguintes: rito pubertário, namoro e casamento, concepção e contracepção, nascimento e maternidade . 


\section{RESULTADOS E DISCUSSÃO}

Tal como foi proposto, este trabalho pretendeu realizar uma escuta sobre possíveis contradições vividas no diálogo estabelecido entre diferentes gerações dos índios Guarani, habitantes da aldeia Morro da Saudade, em relação à maternidade ou à concepção da vida. Esse evento é visualizado sob a ótica sociocultural que estabelece um processo de interação entre a cosmologia que os representa e as ocorrências do presente, apontando para prováveis possibilidades de mudança ou permanências no seio cultural do universo étnico que os caracteriza enquanto grupo.

A maternidade entre os Guarani do Morro da Saudade, como ocorre entre os guarani em geral, tem uma profunda relação com sua cosmologia. Assim sendo, abordá-la, conforme uma perspectiva cultural, é uma empreitada difícil e delicada. Na vida dita cotidiana, o mito, por sua natureza peculiar, ainda é uma referência coletiva, pois segundo VARA ${ }^{10}$ "el mito certifica e inaugura la irrupción de "lo sagrado em el mundo. Origina um tiempo y un espacio "fuertes, una circunstancia vivencialmente intensa, cargada de emotividad y más "verdadera" que otra cualquiera" (p.65); o rito, pelo seu envolvimento diário com a esfera social, cuidando das ações padronizadas, que referenciam à cultura em seus valores e princípios, são dois pilares muito fortes da coesão interna do grupo.

Diante desta perspectiva, o texto, a seguir, não deve ser encarado como uma conclusão definitiva. Por estar vivendo um processo dinâmico de transformação, muitos dos comportamentos observados carecem de consistência, que somente poderá se estabelecer com o passar do tempo. Apresentamos alguns resultados, por vezes acompanhados de indagações que sugerem a complexidade do tema e sua inserção no campo interdisciplinar. Isto tendo em vista a relevância de seu aprofundamento não só para o campo do conhecimento, mas igualmente para o campo das práticas de saúde, de educação, além de outras.

A estreita relação entre a cosmologia e a maternidade mostra-se visível em eventos peculiares. Os pássaros, por exemplo, parecem ter um grande significado simbólico nos eventos ligados à reprodução biológica, sendo intermediários do mundo real e sobrenatural. Segundo relatos de mulheres e homens Guarani-Mbyá da Aldeia Morro da Saudade, quando um pássaro chamado mitâjaryi, canta nas proximidades da casa, a mulher que ouviu seu canto, se não está grávida, logo ficará.

Lúcia, uma jovem mãe, fala de sua experiência:

"Sonhei que peguei dois passarinhos. Pela manhã, quando acordei, contei o sonho para meu marido. Dentro de mim, sabia que ia ficar grávida. Tinha certeza. Talvez de gêmeos, pois foram dois passarinhos. E, alguns dias após este sonho, o mitâ-jaryi* cantava sempre ao redor de minha casa. Logo, logo, eu descobri que estava grávida. A menstruação não veio!".

Analisando os ritos pubertários como práticas sinalizadoras que promovem a iniciação do jovem Guarani na vida adulta, a retomada do ciclo reprodutivo da vida, pretende-se compreender, por meio dessa categoria, os possíveis vínculos que essa fase do ciclo de vida dos Guarani Mbyá estabelece com a maternidade.

Segundo Melatti,

"chama-se de rito de passagem aqueles cerimoniais que marcam a passagem de um indivíduo ou de um grupo de uma situação para outra ou de um mundo cósmico, ou social, para outro. São ritos de passagem aqueles ligados à gestação e ao nascimento, os ritos de iniciação, os ritos matrimoniais, os funerais e vários outros, como os relativos à mudança de estação do ano etc”. (apud ${ }^{l 1}$, p. 51)

O ritual de iniciação da menina GuaraniMbyá, no estudo que realizamos, é parcialmente perceptível ao visitante. A aldeia dispõe de um estabelecimento escolar para o ensino fundamental, e algumas alunas passam por essa fase, durante o período letivo. Quando ocorre a menarca, elas deixam de frequientar as aulas por um período de aproximadamente trinta dias. Habitualmente, a mãe da jovem comunica a sua ausência aos professores, justificando-a como um tempo destinado

+ mitâ-jaryi, expressão cujo significado em Guarani é avó de criança 
para vivência de determinadas práticas culturais. Passado esse período, é comum vê-las transitando nas dependências da escola, carregando sobre a cabeça um pano amarrado, no formato de véu, em razão do corte de cabelo prescrito por ocasião do ritual da puberdade, anunciando socialmente sua emancipação ao status de mulher adulta.

Tradicionalmente, uma das funções simbólicas dos ritos pubertários entre os Guarani é demonstrar o desempenho de papéis que garantirão a sobrevivência de seu povo. No caso da jovem Guarani, o período ritualístico está profundamente integrado à função reprodutora da mulher, que recebe um treinamento ministrado por sua mãe, que a inicia nos ofícios vinculados ao gênero feminino. Nesse período, ela aprende as tarefas do lar, as habilidades manuais que a capacitarão à confecção de uma variedade de artesanatos, cuja renda garantirá a sobrevivência de sua futura prole.

Com referência aos ritos pubertários, observou-se singularidades em relação às diferentes gerações. Diferentemente das experiências relatadas por gerações mais velhas, esses rituais, com suas práticas peculiares, surgem no contexto de novas necessidades, pontuadas como possíveis mudanças que começam a integrar o momento sociocultural vivido no presente.

A jovem Teresa disse que não cortou o cabelo quando teve a primeira menstruação. Os pais não a obrigaram a fazer isso. Disse que gostou, pois não se sentiria muito bem com o cabelo cortado, andando pelas dependências da aldeia.

Aos jovens do sexo masculino questionouse sobre as perspectivas de casamento com uma jovem que não passou pelo ritual da puberdade como prescreve sua cultura, quando da chegada da primeira menstruação. Alguns disseram que não se importariam. Outros se declararam fiéis à tradição, porque a observância do ritual demonstraria que a jovem estaria pronta para casar.

No grupo observado tende-se a ressaltar que o desempenho e aprendizagem das tarefas artesanais e domésticas obedece a uma lógica de gênero, decorrente da cosmovisão que define os papéis que homens e mulheres devem desempenhar no âmbito de sua organização social. No entanto, observouse que as gerações mais velhas tendem a ser mais conservadoras em relação à menina, referindo-se à precocidade com que estas, normalmente, se casam, não estando preparadas para o desempenho do papel feminino dentro do casamento.

Ana, uma senhora de 35 anos, disse que:

"o jovem se casa muito cedo. No meu tempo, esperava ficar com 15 anos. Essa idade era boa para casar. Agora, logo depois que tem a menstruação, a menina já quer casar. Tem menina, aqui, casando com 12, 13 anos. Tem gente que nem casa, vai logo morar junto. $O$ jovem, hoje, é muito desobediente”.

Namoro e casamento trouxeram, enquanto categorias, a possibilidade de análise de algumas práticas culturais que contornam os rituais peculiares a esses acontecimentos e seu vínculo com a concepção da vida. No âmbito de uma perspectiva sociocultural, tornou-se relevante compreender o significado do namoro e do casamento, levando-se em consideração o convívio com outros modelos de relacionamento amoroso, que caracterizam as populações não índias que vivem no entorno da aldeia.

Paula, 15 anos, reflete bem essa dinâmica, ao expressar sua expectativa em relação ao casamento:

"Antes de pensar em casar, pretendo estudar. Quero ser professora. Não posso casar agora. Prefiro escolher um menino da aldeia, quando estiver pronta para o casamento. Quero casar com um Guarani”:

Pedro, 23 anos, tem uma experiência de vida que reforça a impressão de mudança cultural. Ele fez o seguinte relato:

"Casei com a idade de 14 anos". Cedo. Separei quando tinha 19 anos. Com dois filhos. Não tinha muita responsabilidade. Queria casar. E, pronto! Após algum tempo de casado, cheguei à conclusão que o casamento exigia muita responsabilidade. Talvez eu não tivesse preparado para isso. Meus filhos vivem com minha exsogra. Eu ajudo. Minha ex-esposa casou-se novamente. Teve mais filho. Eu, por enquanto, não pretendo casar. Quero estudar. Na verdade, quero ser professor. Depois um veterinário. Muita coisa mudou na aldeia. Hoje, namora-se diferente. Alguns usam até preservativo". 
Percebe-se no discurso do jovem a interpenetração de culturas e adoção de práticas externas. As lideranças, sobretudo do cacique Timóteo, mostram-se apreensivas quanto à forma e à qualidade da convivência estabelecida entre os jovens Guarani e a população não-índia que vive nas proximidades da aldeia.

Viver no entorno de uma grande cidade tem sido um desafio para os Guarani. O perímetro de área demarcada é insuficiente, sendo um fator restritivo à sobrevivência econômica e cultural, diz Timóteo, que, freqüientemente, alerta: "A cidade está chegando! Antigamente nós tínhamos uma auto-sustentação material. Hoje, estamos numa ilha. Preciso gerar emprego na comunidade!"

Timóteo exerce uma liderança espiritual e política na aldeia. Atua como conselheiro nas questões políticas e sociais. Em relação aos jovens e particularidades que envolvem casamento, namoro, relacionamentos relatou que:

"Não proíbo namoro. Reúno, todos os dias, os jovens na "Casa de Reza". Ali, falo para ele da importância de ter um filho e se preparar para receber essa criança. Muito jovens tiveram filhos. O casamento não é brincadeira. Tem que haver uma forte ligação entre o casal. Hoje, quando se casa muito cedo (ele situa casar cedo com a idade de 14 anos), a menina não consegue cuidar dos filhos, passando essa responsabilidade para os avós”.

Essa não é, porém, sua maior preocupação, mas sim a falta de religiosidade entre os jovens.

"A prática da religião deixa o Guarani, equilibrado, vivo. Se esquecer da religião, acaba tudo..."

O desejo de continuar estudando emergiu como uma expectativa presente em quase todos os jovens. Muitos, inclusive, almejam cursar uma faculdade, antes de pensar no compromisso do casamento. Neste aspecto, há indícios muito consistentes de que os padrões culturais da população não índia, sobretudo a que habita no entorno da aldeia e que vive um processo de exclusão similar aos Guarani, foram incorporados, como a busca de ascensão profissional e financeira, em confor- midade com a lógica do processo inerente aos valores das sociedades industriais modernas. E, também, de políticas de ação afirmativa que, na cidade de São Paulo, tem oferecido bolsas de estudo para estudantes indígenas nas Universidades.

Ladeira $^{2}$ relata que os Guarani,

"conscientes da falta de opções, insistem em preservar as pequenas áreas onde foram confinados e que estão longe de garantir o sustento da comunidade, através de atividades produtivas, de conter os recursos ambientais necessários ao seu bem-estar e garantir a sua reprodução física e cultural, segundo seus usos, costumes e tradições, conforme rege o parágrafo 1 do art. 231 da Constituição”. (p. 105)

Schaden ${ }^{12}$ destaca que,

"a aculturação econômica se processa não somente de acordo com a necessidade de fazer face a novas exigências, oriundas do contato com a civilização, mas também como conseqüência mais ou menos direta da perda ou transformação de velhos padrões ou instituições ou mesmo de condições materiais, que torna a velha economia impraticável, obrigando à procura de novas soluções." (p. 54)

“O jovem Guarani, hoje”, diz Tiago,

"não pode ter filho porque falta terra. Nós queremos demarcar terra, mas o branco não deixa. Hoje, nós plantamos algumas coisinhas aqui: mandioca, milho, cenoura, abóbora, banana. Mas não dá para viver. A terra é muito pouca. Como é que nos vamos pensar em ter filhos? Sustentar esses filhos com o quê?".

Schaden ${ }^{12}$ revela que tradicionalmente,

"o casamento entre os Guarani acontece cedo. Entre os Kayová e Mbyà, a mulher pelos 14 anos de idade, o homem pouco mais tarde". Ainda conforme esse autor, "o Guarani não conhece o amor romântico, borboleteia nas relações amorosas e facilmente desmancha o casamento, deixando o filho com a mulher, para unir-se a outra, fatos que, aliás, se agravam com a desorganização social”. (p. 66)

No presente estudo, a precocidade do 
casamento apontada pela população mais velha, como o comportamento cada vez mais comum entre os jovens, pareceu ser uma contradição, pois, na fala dos jovens, o casamento não aparece como desejo imediato. Resta saber, portanto, se a precocidade a que se referem os mais velhos, é decorrente da preocupação pela possível tutela dos netos, citada como um fato real entre os Guarani. Isso ocorre tanto em caso de separação como quando há dificuldades financeiras para sustentálos, uma vez que os filhos nem sempre estão preparados economicamente para arcar com as despesas da casa . Neste sentido, destaca-se o não aprendizado, por parte das meninas, da confecção do artesanato tradicional, cuja venda possibilita algum conforto econômico e, também, sobrevivência.

O jovem Paulo, 20 anos, assim se expressou:

"Quero casar, mas vou esperar uns três anos. Pretendo estudar informática. Ł̀ importante ter um emprego! Só depois, vou pensar em casar".

Ainda no tocante à precocidade dos casamentos, supõe-se que a adesão a modelos inseridos na cultura dos brancos, em que a maternidade na contingência considerada precoce costuma ser assumida pelos avós estaria influenciando a maneira como o jovem Guarani encarava , tradicionalmente, a responsabilidade pela criação e educação dos filhos.

Heilborn et $\mathrm{al}^{13}$, refletindo sobre estatísticas que revelam o aumento da fecundidade do adolescente brasileiro, diz que:

"este fenômeno ganha importância no cenário de mudanças operadas na concepção social das idades e do gênero que redefinem as expectativas sociais depositadas nos jovens nos dias atuais, sobretudo em adolescentes do sexo feminino. Parecem ser precisamente as chances abertas às jovens, no que diz respeito à escolarização, à inserção profissional, ao exercício da sexualidade desvinculado da reprodução, que fundamentam uma nova sensibilidade quanto à idade certa para se ter filhos."(p. 18)

Nesse panorama, a gravidez na adolescência desponta com um desperdício de opor- tunidades, uma subordinação precoce a um papel do qual, durante tantos anos, as mulheres tentaram se desvencilhar. Essa argumentação subestima o fato de esse leque de oportunidades sociais não ser igualmente oferecido para jovens de diferentes classes e, além disso, pressupõe como universal o valor ou o projeto de um novo papel feminino.

Como se apresenta, então, a questão da desigualdade no acesso a esse leque de oportunidades sociais, na contingência específica dessas jovens, procedentes de universos étnicos de sociedades indígenas, onde as lógicas culturais, econômicas e sociais, que regulam seus valores, são literalmente divergentes da sociedades dos não-índios?

Berquó ${ }^{14}$ destaca que:

"a vivência em uma sociedade com altas taxas de separações e divórcios acaba também por levar o jovem a questionar o valor de união civil. Gravidezes, desejadas ou não, ocorridas muito cedo na vida das jovens, podem mudar o curso de suas vidas, levando muitas vezes a uniões precoces, legalizadas ou não, dependendo da opção do casal envolvido, ou de decisões judiciais específicas, colocando os jovens em situações de grande vulnerabilidade.” (p. 93)

Nesse contexto, namorar ou "ficar", por exemplo (comportamento não habitual entre os Guarani), foi apontado como prática usual. E, com ele, o uso da camisinha emerge como alternativa possível entre o grupo de jovens. Relacionar-se sexualmente, portanto, não está restrito ao casamento ou a uniões formalizadas.

A possibilidade de relacionamentos amorosos fora do vínculo do casamento, sobretudo entre a população jovem, parece não ser uma realidade ignorada. $\mathrm{O}$ uso da camisinha, como um método contraceptivo de fácil acesso, e que pode ser comprada às escondidas, foi mencionado, porque traz uma certa segurança em relação à prevenção da gravidez e doenças sexualmente transmissíveis.

Relatos, dos jovens Guarani, ilustram essas afirmações:

"Freqüentemente", encontro camisinhas guardadas debaixo das camas de meus irmãos. Converso com eles sobre o assunto. Digo que é 
melhor usar as camisinhas para não engravidar as meninas. Caso eles engravidem alguma, não vão casar. As meninas não têm como criar os filhos. Portanto, todo cuidado é pouco. Hoje as coisas estão mudadas. Antigamente, o jovem Guarani, homem ou mulher, estava preparado para casar muito cedo. Eles eram orientados pelos pais. Tinham mais responsabilidade. Agora, o namoro é uma curtição. Não tem muito compromisso. A única coisa boa que acho disso é que o fato de não casar muito cedo faz com que eles procurem estudar, aprender profissão. $O$ importante é buscar um meio de sobrevivência."

Essa abordagem da sexualidade, parcialmente desvinculada da reprodução, configura uma condição diferenciada entre a população jovem Guarani, em função do contato com outras populações que vivem no entorno da aldeia?

A convivência interativa com outros grupos populares, que residem no entorno da aldeia e em bairros adjacentes, o poder da mídia, especificamente a televisão, e outros meios de comunicação, engendram algumas contradições no interior da própria aldeia, fomentando possíveis readaptações no contexto sociocultural onde esses jovens vivenciam esta fase de suas vidas. A passagem para o mundo adulto não só os induz a pensar em outras necessidades e possibilidades como remete aos líderes e aos mais velhos. Estabelece-se um novo contato, em que gerações mais velhas e os jovens possam atuar como protagonistas na preservação adaptada de sua própria história e etnia.

A provável vinculação da menarca à possibilidade da realização do casamento - uma vez que a menarca anuncia o status de adulto para a mulher - requer uma maior reflexão, para entender, por intermédio das falas dos jovens, de ambos os sexos, expostos no corpo do trabalho, como hoje esse fenômeno é encarado. Não contempla apenas a tradição, no sentido de rigidez, mas emerge como outras necessidades. Dentre estas, a possibilidade de estudar foi apontada como uma meta almejada. E, na seqüência, a possibilidade de ter um emprego, que garanta a sobrevivência.

Os jovens que não se casaram cedo têm expectativas diferentes em relação à vida amo- rosa. Não concebem o relacionamento amoroso como uma possibilidade de casamento. Fala-se em namoros, com possibilidade de começo e fim. Fazem uso livre, inclusive, da prerrogativa de efetivar ou terminar uma relação, valendo-se de bilhetes, algo inovador nas sociedades cuja comunicação prima pela oralidade.

Assim, o que se percebe é uma geração de jovens que não visam apenas ao casamento tradicional, imediato, mas buscam vivenciar outras modalidades de relacionamento amoroso. Os contraceptivos, com destaque para a camisinha, talvez tenham estimulado o "ficar", aqui também interpretado como um namoro, com possibilidade ou não de relacionamento sexual.

Sabe-se que o campo da saúde reprodutiva é um espaço dinâmico que, em face de sua complexidade, implica em diálogos permanentes entre várias áreas de conhecimento ou disciplinas , para dar conta de seu objeto e orientar práticas condizentes, que contemplem a diversidade e pluralidade, de modo a apreender as especificidades que caracterizam a diversidade das populações.

Coimbra et $\mathrm{al}^{15}$ destacam que:

"em determinados contextos, o processo de urbanização indígena, crescente em várias regiões do país, pode implicar uma maior inserção da mulher no mercado de trabalho, sem que se verifique, contudo, um crescimento equivalente de seu poder político no seio do grupo familiar ou étnico. Esse processo, ainda muito pouco conhecido, certamente traz em seu bojo novos agravos à saúde reprodutiva da mulher indígena" $(p .15-36)$

Quanto à questão da maternidade, enquanto desejo, planejamento, participação, rejeição e outros fatores componentes do amplo universo que contorna esse evento, supõe-se que a dimensão mítica e ritualística ainda esteja presente entre os Guarani, embora os rituais que permeiam as diversas fases da maternidade parecem sofrer mudanças.

Tradicionalmente, o Guarani costuma ter prole numerosa. Constatamos, no entanto, indícios de mudanças. O desejo de planejar o número de filhos, por exemplo, não aparece como uma possibilidade remota. Patrícia, de 29 anos, por exemplo, diz que pretende ter uma filha. "Depois, 
não quero mais filhos. Tenho 3 meninos. Está bom. Aqui, as mulheres mais velhas esperam chegar a ter 10,11 . Só depois de ter essa quantidade de filho, diz que não quer mais. Eu, não! Só quero mais uma menina. E acabou!".

Quanto à contracepção, observou-se, entre os mais jovens, o desejo de poder controlar a prole. No entanto, a opção pelos métodos contraceptivos, enquanto decisão consciente, apresentou-se contraditória nos discursos apresentados entre as diferentes gerações. Enquanto os jovens consideram melhores aqueles métodos adotados entre brancos, os mais velhos preconizam os métodos tradicionais. As ervas, como recursos próprios da cultura, parecem não estar mais inseridos nos costumes diários como forma de resolver essa provável demanda requerendo, pois, uma escuta que localize a possibilidade de resgate e, portanto, de utilização.

Diante do que vimos, ouvimos, registramos e analisamos, ponderamos que seria irresponsabilidade apontar conclusões definitivas e fechadas, em relação a comportamentos e práticas de uma cultura que se encontra em processo dinâmico de mudança e permanência.

Segundo Junqueira ${ }^{16}$,

"se não é possível adivinhar o futuro, pode-se pelo menos indicar os contornos da dinâmica cultural. Para isso, é preciso remover um velho obstáculo conceitual, pois há tempos que, por enfeixarem muitas atividades, valores e processos num mesmo conjunto, dificultam distinções que precisam ser feitas. É o caso, por exemplo, do conceito de cultura, comumente empregado para designar o modo de viver de um povo e que, com freqüência, sugere a existência de um sistema coerente e equilibrado de ações, pensamentos e valores. Como se 'cultura' e seu correlato, ainda mais conservador, a 'tradição', impusessem uma ordem estrita no social, inibindo transgressões e inovações, tanto no âmbito do comportamento como do pensamento". ( p. 17-34).

Refletindo sobre a CIPD (Conferência Internacional sobre População e Desenvolvimento), que abordou temas mais abrangentes, como saúde e direitos sexuais e permanências que essa população concebe no contexto presente, em todas as condições de desconforto exaustivamente observadas fica o questionamento sobre: o que os Guarani têm para nos dizer em relação à sua reprodução?

Nossa proposta visou fazer essa reflexão, com o intuito de suscitar outras questões e reflexões, que tragam a esse grupo étnico melhores condições para resolver e contornar suas dificuldades e necessidades internas e, também, no contato interétnico. Nessa ação, seu universo cosmológico deve ser a referência primordial; a cultura pode tornar-se um arranjo dinâmico, com possibilidades de acertos e preservação, visando ao bem-estar de todos que a integram. Continuamos, então, a perguntar... Reprodução e Transmissão Cultural: o que os jovens Guarani, residentes na periferia de São Paulo, têm a dizer?

\begin{abstract}
This is a qualitative study conducted to understand issues relating to the maternity and reproductive behavior of youths belonging to the Guarani-Mbyá ethnic group, inhabitants of Aldeia Morro da Saudade, a village located on the periphery of the city of São Paulo. The study aims to unveil the meanings attributed to maternity by the different Guarani generations, which live in an area of restricted territorial demarcation, establishing a daily interaction with other cultural patterns practiced by a population of non-Indians who live around the village. This event is seen from a socio-cultural point of view, which establishes a process of interaction between the cosmology that represents them and the current occurrences, pointing to probable possibilities of change, or cultural maintenances inside the ethnic universe which characterizes them as a group.
\end{abstract}

Key words: Youth and reproduction. Guarani-Mbyá Ethnic Group. Reproductive health. Ritual Practices. Indian health. 


\section{REFERÊECIAS}

1. Farias IS. Breve relato sobre os GuaraniMbyá. Paraty - RJ. Núcleo de Estudos em Saúde de Populações [Indígenas/ENSP; 1996.

2. Ladeira MI. Espaço geográfico Guarani-Mbyá: significado, constituição e uso[doutorado]. São Paulo: Faculdade de Filosofia Letras e Ciências Humanas da USP; 2001.

3. Ribeiro D. Os índios e a civilização. A integração das populações indígenas no Brasil. Petrópolis: Vozes; 1986

4. Schaden E. Problemas de aculturação no Brasil. $2^{a}$ ed. São Paulo: Universidade de São Paulo - Escola de Comunicações e Artes; 1972 (Série Cultura Geral).

5. Barbosa CGA, Barbosa MA . [Prefácio] In: Nimuendaju C. As lendas da criação e destruição do mundo como fundamentos da religião dos Apapocúva- Guarani. São Paulo: Hucitec/EDUSP ; 1987. p. ix-xiv.

6. Pagliaro H. A revolução demográfica dos povos indígenas do Brasil: a experiência dos Kaiabi do Parque Indígena do Xingu- Mato Grosso-1970-1999[tese]. São Paulo: Faculdade de Saúde Pública da Universidade de São Paulo; 2002.

7. Lopez GMA. A fecundidade entre os Guarani: um legado de Kunhankarai [tese]. Rio de Janeiro: Escola Nacional de Saúde Pública; 2000.

8. Atkinson P, Hammersley M. In: Denzin NK, Lincoln YS. Ethnography and participant observation. London: Sage Publications; 1994. p.248-61.
9. Spink MJP, organizadora. Práticas discursivas e produção de sentidos no cotidiano aproximações teóricas e metodológicas. São Paulo: Cortez; 1999. p.63-92.

10. Vara A. La construcción Guarani de la realidad. Volume III. Asunción, Paraguay: CEADUC- Centro de Estúdios Antropológicos de la Universidad Católica N.S. de la Asunción; 1984. p.61-71.

11. Azevedo MAP. Maternidade e transmissão cultural: o que os Guarani, residentes na periferia da capital paulista, têm a dizer... : 2004[dissertação]. São Paulo: Faculdade de Saúde Pública da Universidade de São Paulo. p.51

12. Schaden E. Aspectos fundamentais da cultura Guarani. $3^{a}$ ed. São Paulo: EPU - Editora Pedagógica Universitária Ltda./EDUSP Editora da Universidade de São Paulo; 1974.

13. Heilborn ML, Salem T, et al. Horizontes antropológicos. In: Aproximações socioantropológicas sobre a gravidez na adolescência. Porto Alegre: UFRGS; 2002. p.13-45

14. Berquó E. Jovens acontecendo na trilha das políticas públicas. Brasília: CNPD; 1998. p.93

15. Coimbra Jr CEA, Santos RV. Cenários e tendências da saúde e da epidemiologia dos povos indígenas no Brasil. In: Escobar AL; Santos RV, Coimbra Jr. CEA, organizadores. Epidemiologia e saúde dos povos indígenas no Brasil. Rio de Janeiro: FIOCRUZ; 2004 p.15-36.

16. Junqueira C. Antropologia fora da Universidade. In: Silva AAd, Chaia M, organizadores. Sociedade, cultura e política: ensaios críticos. $1^{a}$ ed. São Paulo: EDUC; 2004. v.1, p.17-34

Recebido em 26/10/2006 Modificado em 20/04/2007 Aprovado em 24/04/2007 